\title{
A study of the incidence and prognostic value of HER-2 overexpression in patients with gastric adenocarcinoma in Odisha
}

\author{
Sangram Keshari Panda ${ }^{*}$, Amita Panda ${ }^{2}$, Mishra JN ${ }^{1}$ and Pallavi Bhuyan ${ }^{3}$ \\ ${ }^{1}$ PG Resident, Department of General Surgery, SCB Medical College, Cuttack, Odisha, India-753003 \\ ${ }^{2}$ PG Resident, M.K.C.G.Medical College, Berhampur, Odisha, India \\ ${ }^{3}$ Department of Pathology, SCB Med college, Cuttack, India
}

\begin{abstract}
Aim: Gastric cancer is the fourth common cancer and is the second leading cause of cancer-related mortality worldwide. Majority of the patients are diagnosed when the cancer is at an inoperable or metastatic stage. Median survival of patients with advanced tumors remains poor. Only 7-10 months. The best promise to improve this poor survival is provided by new agents acting against specific molecular targets. Of these, HER-2 is currently in the spotlight. Frequency of HER2 expression in gastric cancer has been reported from different geographic zones with a range of $6 \%$ to $35 \%$. The purpose of this study was to evaluate the frequency of HER2 expression in gastric adenocarcinoma and its association with various clinicopathological characteristics and survival in Odisha.

Methods: A total of 150 patients undergoing gastric resection surgery (radical/palliative) for gastric adenocarcinoma at S.C.B. Medical College and hospital, Cuttack were included in this study. They were prospectively evaluated using Immunohistochemistry (IHC). HER2 overexpression was confirmed in 28 of 150 (18.7\%) patients. Significantly different HER2 positivity rates were observed when comparing intestinal-type gastric cancers with diffuse/mixed-type cancers (28.6\% vs $12.8 \%$, $P=0.01)$, and moderate-differentiated cases with poorly differentiated cases $(38.7 \%$ vs $16.7 \%, P=0.01)$. Positive reactivity with anti cerbB-2 antibody was significantly more frequent in UICC stage-III (40\%, $p=0.005)$. No relationship was observed between the HER2 positivity rate and sex, age, tumor site. The HER2 positive gastric cancer patients did not show statistically significant reductions in mean survival times,1-year or 2-year survival rates. The well differentiated HER2 positive patient group exhibited shorter mean survival time (18.5 mo vs $27.5 \mathrm{mo}$ ) and lower 1-year and 2-year survival rates compared to the HER2 negative group (84.42\% vs $96.00 \% ; 50.65 \%$ vs $86.89 \% ; P=0.0123)$.
\end{abstract}

Conclusion: HER-2/neu overexpression is common in gastric carcinoma and more prevalent in intestinal and moderate differentiated subtypes. HER2 status has a mild impact on gastric cancer patient survival and may not constitute an independent prognostic factor in gastric cancer patients.

\section{Introduction}

Gastric cancer is the fourth common cancer and is the second leading cause of cancer-related mortality worldwide. It causes about one million deaths worldwide per year [1]. The highest incidence of gastric cancer is seen in northeast Asia. Annual incidence rate of gastric cancer in various centers across India is 10.6 per 100,000 population. Majority of the patients are diagnosed when the cancer is at an inoperable or metastatic stage [2] and despite benefits of palliative radiotherapy \& chemotherapy, survival of patients with advanced tumors remains poor (median survival7-10 months) [3]. The best promise to improve this poor survival is provided by new agents acting against specific molecular targets. Of these, HER-2 is currently in the spotlight.

Her2/neu over-expression was first described in 1886 [4] using immunohistochemistry. Since then research is on and it is turning out to be a useful molecule for which targeted therapy in the form of Trastuzumab is available. Her2/neu (c-erbB2) is a proto-oncogene located on chromosome $17 \mathrm{q} 21$ [5]. Her2/neu encodes a $185-\mathrm{kDa}$ transmembrane tyrosine kinase receptor, a member of the Epidermal Growth Factor Receptor Family (EGFRs), comprises four members: HER1 (EGFR), HER2, HER3 and HER4. They are involved in various aspects of tumor cell biology; cell proliferation, apoptosis, adhesion, migration and differentiation [5]. HER-2 amplification and/or over expression have also been observed in colon [6], bladder [7], ovarian
[8], Fallopian tube [9], endometrium [10], lung [11], uterine cervix [12], head and neck [13], prostate [14], pancreatic [15], salivary gland [16] and esophageal [17] and gastric carcinoma [18].

A number of studies have analyzed Her2/neu overexpression in gastric carcinoma, and the rate of Her2 positivity is variable, ranging from $6 \%$ to $35 \%$. The largest ongoing international trial which enrolled 2,992 gastric or Gastro-Esophageal Junction Cancer (GEJ), defined $21.7 \%$ of evaluable tumor samples as Her2 positive[19].

Recent evidence has shown that the HER2 plays a key role in the oncogenesis of a subset of different cancer types. Most importantly, HER2 has become a prognostic and predictive factor in breast cancer where the HER 2 status is typically measured by Immunohistochemistry (IHC) or in situ Hybridization (ISH). Trastuzumab (Herceptin) is a monoclonal antibody which specifically targets HER2 protein by directly binding the extracellular domain of the receptor. Trastuzumab enhances survival rates in both primary and metastatic HER2-

Correspondence to: Dr. Sangram Keshari Panda, MS, PG Resident, Department of General Surgery, SCB Medical College, Cuttack, Odisha, India-753003, Tel: +91-9776636938; E-mail: drsangram83@gmail.com

Received: May 28, 2015; Accepted: July 07, 2015; Published: July 10, 2015 
positive breast cancer patients has led to investigate its antitumor activity in patients with HER2 positive cancers, including gastric adenocarcinomas.

HER2 inhibition is playing a significant role as a new treatment option for gastric cancer. Numerous countries have approved the use of Herceptin for the treatment of gastric cancer and increasingly, HER2 has become a "hot" research topic.

The aim of our study was to evaluate the frequency of HER2 expression in gastric adenocarcinoma and its association with various clinicopathological characteristics and survival in Odisha.

\section{Methods}

A consecutive prospective series of 150 patients undergoing gastric resection surgery (radical/palliative) for gastric adenocarcinoma at S.C.B. Medical College \& Hospital, Cuttack, India were included in this study. Expression of HER2 in the histological specimen and correlation between the expression of HER2 \& clinicopathological parameters (age, gender, tumor location, histological differentiation and pTNM classification) were evaluated in these patients.

Immunohistochemical (IHC) analysis for HER2 was performed on formalin-fixed paraffin-embedded sections of surgical specimens. Positive controls included breast cancer tissue known to exhibit high levels of her2. For scoring, Hofmann's HER2 gastric cancer scoring system was adopted. All cases showing IHC3+ were defined as HER2 positive.

The study was approved by the Institutional review board and hospital ethics committee.

\section{Results}

The mean age was 63.6 years (from 26 to 82 ) and the male/ female ratio was 1.46: 1 ( 89 men, 61 women). $12.6 \%$ of cases were stage I, $22 \%$ stage II, $23.4 \%$ stage III, and $42 \%$ stage IV. According to Lauren's classification, 56 tumors (37.3\%) were intestinal, 94 (62.7\%) were diffuse and mixed-type carcinomas. $23(15 \%)$ tumors were well differentiated, 31 (20.7\%) were moderate-differentiated, 96 (64\%) were signet ring and poorly-differentiated. From 150 tumors, 47 were located at the body, 52at the GEJ \& Cardia and 51 were at pylorus. In 28 out of 150 samples, (18.7\%) HER-2/neu protein overexpression (IHC score $3+)$ was observed.

\section{Correlation of HER2 with clinicopathological characteristics}

Significantly different HER2 positivity rates were observed when comparing intestinal-type gastric cancers with diffuse/mixed-type cancers $(28.6 \%$ vs $12.8 \%, P=0.01)$, and moderate-differentiated cases with poorly differentiated cases $(38.7 \%$ vs $16.7 \%, P=0.01)$. Positive reactivity with anti cerbB-2 antibody was significantly more frequent in UICC stage-III ( $40 \%, \mathrm{p}=0.005)$. No relationship was observed between the HER2 positivity rate and sex, age, tumor site $(P>0.05$; Table 1$)$.

\section{Survival analysis}

Of our 150 gastric cancer patients, 22 cases were lost in follow-up. The median survival time for the remaining 128 patients was 18 months (range: 0-33 mo). During the follow-up time, 48 deaths occurred (32\%), 45 of which were disease-related. One patient died of perioperative pulmonary infection, and two cases died of heart disease and multiple organ failure, respectively. The median survival time of the HER2 positive (22 cases) and negative groups (106 cases) was $17 \mathrm{mo}$ and 18.5 mo respectively. Nevertheless, the HER2 positive gastric cancer patients
Table 1. Correlation of human epidermal growth factor receptor-2 expression with clinicopathological characteristics.

\begin{tabular}{|l|c|c|c|c|c|}
\hline $\begin{array}{l}\text { Clinicopathological } \\
\text { characteristics }\end{array}$ & N (\%) & HER-2 positive & Her-2 negative & $\chi^{2}$ & p-value \\
\hline Sex & $89(59 \%)$ & $20(22.5 \%)$ & $69(77.5)$ & 1.96 & 0.1 \\
\hline Male & $61(41)$ & $8(13.2)$ & $53(86.8)$ & & \\
\hline Female & & & & & \\
\hline Age in yrs & $42(28)$ & $10(23.8)$ & $32(76.2)$ & 0.91 & 0.1 \\
\hline$<60$ & $108(72)$ & $18(16.6)$ & $90(83.4)$ & & \\
\hline$\geq 60$ & & & & & \\
\hline Tumor site & $47(31.3)$ & $10(66.7)$ & $37(33.3)$ & 0.61 & 0.1 \\
\hline Body & $52(34.7)$ & $8(15.4)$ & $44(84.6)$ & & \\
\hline GEJ \&Cardia & $51(34)$ & $10(19.6)$ & $41(80.4)$ & & \\
\hline Pylorus & & & & & \\
\hline Lauren classification & $35(23)$ & $4(12.1)$ & $29(87.9)$ & & \\
\hline Intestinal & $56(37.3)$ & $16(28.6)$ & $40(71.4)$ & 5.14 & 0.01 \\
\hline Diffuse/ Mixed & $94(62.7)$ & $12(12.8)$ & $82(87.2)$ & & \\
\hline Tumor Differentiation & & $14(40)$ & $21(60)$ & & \\
\hline Well diff. & $23(15.3)$ & 0 & & & \\
\hline Moderate diff. & $31(20.7)$ & $12(38.7)$ & $19(61.3)$ & & \\
\hline Signet ring \& poor diff. & $96(64)$ & $16(16.7)$ & $80(83.3)$ & & \\
\hline UICC Staging & & & & \\
\hline I & $35(12.6)$ & & & \\
\hline II & & & & \\
\hline III & & & & \\
\hline IV & & & & \\
\hline
\end{tabular}

*HER2, human epidermal growth factor 2; diff., differentiated; GEJ, gastroesophageal junction.

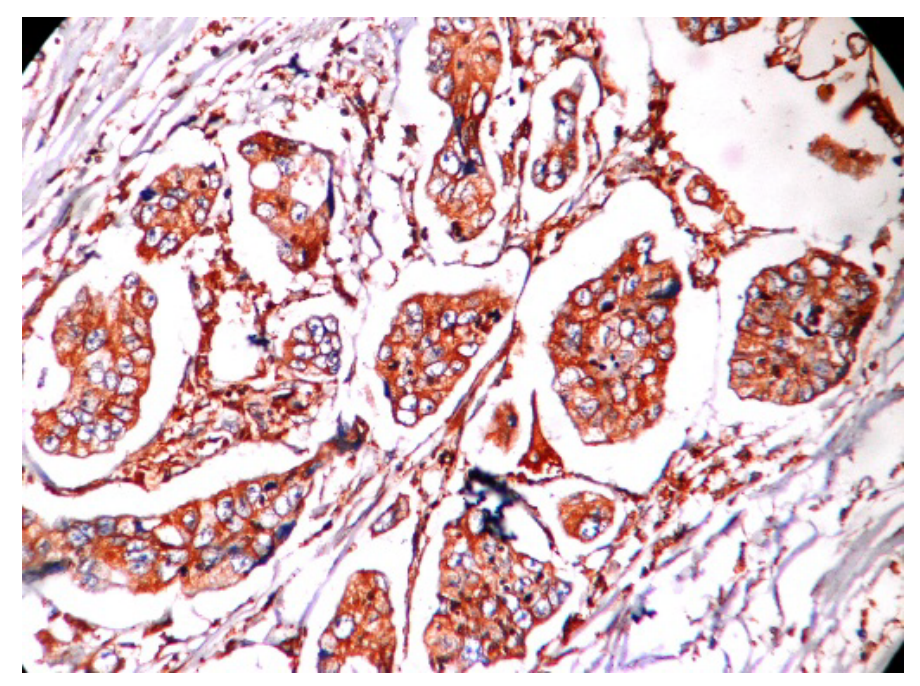

Figure 1. Microphotograph showing intestinal type adenocarcinoma HER2 score 3+.

did not show statistically significant reductions in mean survival times, nor lower 1-year or 2-year survival rates. Furthermore, no statistically significant differences were observed in overall survival times between 


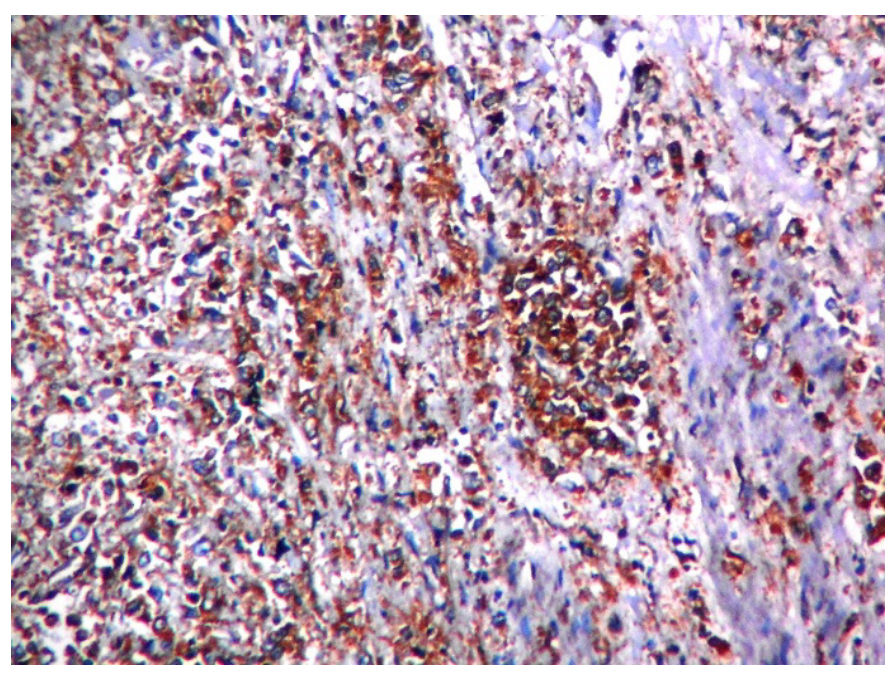

Figure 2. Microphotograph showing diffuse type adenocarcinoma HER2 score $3+$

the HER2 positive and negative groups $\left(\chi^{2}=0.9157, P=0.3386\right)$. Within the well differentiated gastric cancer patient group, patients with HER2 tumor positivity had poorer outcomes than those with HER2 negative tumors. The well differentiated HER2 positive patient group exhibited shorter mean survival time (18.5 mo vs $27.5 \mathrm{mo}$ ) and lower 1-year and 2-year survival rates compared to the HER 2 negative group $(84.42 \%$ vs $96.00 \% ; 50.65 \%$ vs $86.89 \% ; P=0.0123)$. The median survival time of the HER2 positive group did not show any statistical associations when compared to the subgroups of sex, age, tumor site, TNM classification, depth of invasion, lymph node metastases and distant metastasis in gastric cancer. Within the poorly differentiated and diffuse/mixed type gastric cancer patient groups, no statistically significant differences were observed between the HER2 positive and HER2 negative groups.

\section{Discussion}

In the present study, IHC scoring criteria followed that of Hofmann [20] which is considered to be the most appropriate HER2 scoring system in human gastric cancer. Furthermore, to ensure the reliability of our results, we followed the guidelines on HER2 detection in breast cancer, recommended by the American Society of Clinical Oncology/ College of American Pathologists (ASCO/CAP) [21].

Herceptin (trastuzumab) is a recombinant human monoclonal antibody designed to target and block the function of HER2 by directly binding to the extracellular domain of the receptor [22,23]. It has been used for the treatment of HER2 overexpressing breast cancer for more than 10 years and was approved by the European Medicines Agency [24] in 2010 for use in combination with capecitabine or 5-FU and cisplatin for metastatic gastric or GE junction cancers, based on data from the "ToGA" clinical trial. The exact anti-tumor mechanism of Herceptin is not fully understood, however some mechanisms have been postulated [23,25-29] including interruption of HER2 mediated cell signaling pathways and cell cycle progression; induction of antibody-dependent cell-mediated cytotoxicity and apoptosis; induction of anti-angiogenesis effects and increasing receptor turnover by endocytosis. As clinical surgeons, we should be readily and accurately able to identify which patients are suitable for Herceptin treatment. An accurate and reliable HER2 scoring system, together with clinical information, may help us to better determine whether a gastric cancer patient is a potential candidate for targeted therapy using Herceptin.
The relationship between HER2 gene amplification and protein expression in gastric cancer patients is controversial [30,31]. Nevertheless, more recent studies have reported a high concordance between gene amplification and protein overexpression using FISH and IHC approaches [32-34]. Indeed, the ToGA trial [35] (which recruited the largest population of gastric cancer patients to date-3807) reported a HER2 FISH and IHC concordance rate of $87.5 \%$, and further reported that HER2 IHC3+ cases were almost all entirely HER2 gene amplified (97.5\% of cases) [29]. In our study, HER2/neu status was determined by immunohistochemistry and all IHC $3+$ tumors are accepted as HER2/neu positive cases. Out of 150 cases 28 cases (18.7\%) show HER2/neu 3+, 122 cases were HER2/neu negative or HER2/neu 1+ and no cases showed HER2/neu 2+ score. In our study, no relationship was observed between HER2 positivity and sex, age and tumor site $(P>0.05)$. However, intestinal-type and moderate-differentiated gastric cancer cases showed a higher HER2 positive rate than diffuse/mixedtype and poorly-differentiated cancer cases respectively. Of interest, the ToGA trial reported a higher HER2 positivity rate in GE junction cancers compared to other gastric cancers $(33.2 \%$ vs $20.9 \%, P<0.001)$ [36]. Our study, as well as that of another group [37], showed no statistically significant difference between HER2 positivity and the gastric tumor site.

A review of 35 published studies, which evaluated the prognostic value of HER2, indicated no differences in the majority of studies, with regard to Overall Survival (OS). Two studies identified a longer OS, while 13 (37\%) observed a significantly poorer OS [38]. Whilst our study did not show any correlation between HER2 status and overall survival, patients with well-differentiated HER2 positive tumors showed poorer survival times compared to patients with HER2 negative tumors. We speculate that HER2 status has a mild impact on gastric cancer patient survival and may not constitute an independent prognostic factor in gastric cancer patients. Clearly, further research is required to explain the impact of HER2 on development and prognosis of gastric cancer.

\section{Conclusion}

HER2 inhibition is playing a significant role as a new treatment option for gastric cancer. Numerous countries have approved the use of Herceptin for the treatment of gastric cancer. To date, there have been limited studies to determine any correlations of HER2 expression with clinicopathological characteristics and prognosis in Indian patients with resectable gastric cancer. Intestinal type, moderate-differentiated and Stage-III gastric cancer patients showed a higher HER2 positivity rate and thus could represent ideal candidates for targeted-therapy using Herceptin. HER2 status has a mild impact on gastric cancer patient survival and may not constitute an independent prognostic factor.

\section{Limitation of our study}

The gold standard test (FISH) could not be done, as was not available in our setup, for confirmation of HER2/neu overexpression.

\section{References}

1. Kamangar F, Dores GM, Anderson WF (2006) Patterns of cancer incidence, mortality, and prevalence across five continents: defining priorities to reduce cancer disparities in different geographic regions of the world. J Clin Oncol 24: 2137-2150. [Crossref]

2. Hohenberger P, Gretschel S (2003) Gastric cancer. Lancet 362: 305-315. [Crossref]

3. Enzinger PC, Mayer RJ (2003) Esophageal cancer. $N$ Engl J Med 349: 2241-2252. [Crossref]

4. Graus-Porta D, Beerli RR, Daly JM, Hynes NE (1997) ErbB-2, the preferred 
heterodimerization partner of all ErbB receptors, is a mediator of lateral signaling. EMBO J 16: 1647-1655. [Crossref]

5. Gravalos C, Jimeno A (2008) HER2 in gastric cancer: a new prognostic factor and a novel therapeutic target. Ann Oncol 19: 1523-1529. [Crossref]

6. Schuell B, Gruenberger T, Scheithauer W, Zielinski Ch, Wrba F (2006) HER 2/neu protein expression in colorectal cancer. BMC Cancer 6: 123. [Crossref]

7. Eltze E, Wülfing C, Von Struensee D, Piechota H, Buerger H, et al. (2005) Cox-2 and Her2/neu co-expression in invasive bladder cancer. Int $J$ Oncol 26: 1525-1531. [Crossref]

8. McKenzie SJ, DeSombre KA, Bast BS, Hollis DR, Whitaker RS, et al. (1993) Serum levels of HER-2 neu (C-erbB-2) correlate with overexpression of p185neu in human ovarian cancer. Cancer 71: 3942-3946. [Crossref]

9. Nowee ME, Dorsman JC, Piek JM, Kosma VM, Hämäläinen K, et al. (2007) HER-2/ neu and p27Kip1 in progression of Fallopian tube carcinoma: an immunohistochemical and array comparative genomic hybridization study. Histopathology 51: 666-673. [Crossref]

10. HetzelDJ, Wilson TO, Keeney GL, Roche PC, Cha SS, et al. (1992) HER-2/neu expression: a major prognostic factor in endometrial cancer. Gynecol Oncol 47: 179185. [Crossref]

11. Hirashima N, Takahashi W, Yoshii S, Yamane T, Ooi A (2001) Protein overexpression and gene amplification of c-erb B-2 in pulmonary carcinomas: a comparative immunohistochemical and fluorescence in situ hybridization study. Mod Pathol 14: 556-562. [Crossref]

12. Mitra AB, Murty VV, Pratap M, Sodhani P, Chaganti RS (1994) ERBB2 (HER2/neu) oncogene is frequently amplified in squamous cell carcinoma of the uterine cervix. Cancer Res 54: 637-639. [Crossref]

13. Beckhardt RN, Kiyokawa N, Xi L, Liu TJ, Hung MC, et al. (1995) HER-2/neu oncogene characterization in head and neck squamous cell carcinoma. Arch Otolaryngol Head Neck Surg 121: 1265-1270. [Crossref]

14. Jorda M, Morales A, Ghorab Z, Fernandez G, Nadji M, et al. (2002) Her2 expression in prostatic cancer: a comparison with mammary carcinoma. J Urol 168: 1412-1414. [Crossref]

15. Yamanaka Y, Friess H, Kobrin MS, Büchler M, Kunz J, et al. (1993) Overexpression of HER2/neu oncogene in human pancreatic carcinoma. Hum Pathol 24: 1127-1134. [Crossref]

16. Cornolti G, Ungari M, Morassi ML, Facchetti F, Rossi E, et al. (2007) Amplification and overexpression of HER2/neu gene and HER2/neu protein in salivary duct carcinoma of the parotid gland. Arch Otolaryngol Head Neck Surg 133: 1031-1036. [Crossref]

17. Reichelt U, Duesedau P, Tsourlakis MCh, Quaas A, Link BC, et al. (2007) Frequent homogeneous HER-2 amplification in primary and metastatic adenocarcinoma of the esophagus. Mod Pathol 20: 120-129. [Crossref]

18. Jaehne J, Urmacher C, Thaler HT, Friedlander-Klar H, Cordon-Cardo C, et al. (1992) Expression of Her2/neu oncogene product p185 in correlation to clinicopathological and prognostic factors of gastric carcinoma. J Cancer Res Clin Oncol 118: 474-479. [Crossref]

19. Ménard S, Casalini P, Campiglio M, Pupa S, Agresti R, et al. (2001) HER2 overexpression in various tumor types, focussing on its relationship to the development of invasive breast cancer. Ann Oncol 12: S15-S19. [Crossref]

20. Hofmann M, Stoss O, Shi D, Büttner R, van de Vijver M, et al. (2008) Assessment of a HER2 scoring system for gastric cancer: results from a validation study. Histopathology 52: 797-805. [Crossref]
21. Wolff AC, Hammond ME, Schwartz JN, Hagerty KL, Allred DC, et al. (2007) American Society of Clinical Oncology/College of American Pathologists guideline recommendations for human epidermal growth factor receptor 2 testing in breast cancer. Arch Pathol Lab Med 131: 18-43. [Crossref]

22. Tai W, Mahato R, Cheng K (2010) The role of HER2 in cancer therapy and targeted drug delivery. J Control Release 146: 264-275. [Crossref]

23. Meza-Junco J, Au HJ, Sawyer MB (2009) Trastuzumab for gastric cancer. Expert Opin Biol Ther 9: 1543-1551. [Crossref]

24. Fujita T (2010) Trastuzumab for gastric cancer treatment. Lancet 376: 1735. [Crossref]

25. Fujimoto-Ouchi K, Sekiguchi F, Yasuno H, Moriya Y, Mori K, et al. (2007) Antitumor activity of trastuzumab in combination with chemotherapy in human gastric cancer xenograft models. Cancer Chemother Pharmacol 59: 795-805. [Crossref]

26. Kim SY, Kim HP, Kim YJ, Oh do Y, Im SA, et al. (2008) Trastuzumab inhibits the growth of human gastric cancer cell lines with HER2 amplification synergistically with cisplatin. Int J Oncol 32: 89-95. [Crossref]

27. Hudis CA (2007) Trastuzumab--mechanism of action and use in clinical practice. $N$ Engl J Med 357: 39-51. [Crossref]

28. Lange T, Nentwich MF, Lüth M, Yekebas E, Schumacher U (2011) Trastuzumab has anti-metastatic and anti-angiogenic activity in a spontaneous metastasis xenograft model of esophageal adenocarcinoma. Cancer Lett 308: 54-61. [Crossref]

29. Croxtall JD, McKeage K (2010) Trastuzumab: in HER2-positive metastatic gastric cancer. Drugs 70: 2259-2267. [Crossref]

30. Lemoine NR, Jain S, Silvestre F, Lopes C, Hughes CM, et al. (1991) Amplification and overexpression of the EGF receptor and c-erbB-2 proto-oncogenes in human stomach cancer. Br J Cancer 64: 79-83. [Crossref]

31. Kameda T, Yasui W, Yoshida K, Tsujino T, Nakayama H, et al. (1990) Expression of ERBB2 in human gastric carcinomas: relationship between p185ERBB2 expression and the gene amplification. Cancer Res 50: 8002-8009. [Crossref]

32. Albarello L, Pecciarini L, Doglioni C (2011) HER2 testing in gastric cancer. Adv Anat Pathol 18: 53-59. [Crossref]

33. Yano T, Doi T, Ohtsu A, Boku N, Hashizume K, et al. (2006) Comparison of HER2 gene amplification assessed by fluorescence in situ hybridization and HER2 protein expression assessed by immunohistochemistry in gastric cancer. Oncol Rep 15: 65-71. [Crossref]

34. Tafe LJ, Janjigian YY, Zaidinski M, Hedvat CV, Hameed MR, et al. (2011) Human epidermal growth factor receptor 2 testing in gastroesophageal cancer: correlation between immunohistochemistry and fluorescence in situ hybridization. Arch Pathol Lab Med 135: 1460-1465. [Crossref]

35. Bang YJ, Van Cutsem E, Feyereislova A, Chung HC, Shen L, et al. (2010) Trastuzumab in combination with chemotherapy versus chemotherapy alone for treatment of HER2positive advanced gastric or gastro-oesophageal junction cancer (ToGA): a phase 3 , open-label, randomised controlled trial. Lancet 376: 687-697. [Crossref]

36. Meza-Junco J, Au HJ, Sawyer MB (2009) Trastuzumab for gastric cancer. Expert Opin Biol Ther 9: 1543-1551. [Crossref]

37. Marx AH, Tharun L, Muth J, Dancau AM, Simon R, et al. (2009) HER-2 amplification is highly homogenous in gastric cancer. Hum Pathol 40: 769-777. [Crossref]

38. Chua TC, Merrett ND (2012) Clinicopathologic factors associated with HER2-positive gastric cancer and its impact on survival outcomes--a systematic review. Int J Cancer 130: 2845-2856. [Crossref]

Copyright: (C2015 Panda SK. This is an open-access article distributed under the terms of the Creative Commons Attribution License, which permits unrestricted use, distribution, and reproduction in any medium, provided the original author and source are credited. 